\title{
Antibody response to Staphylococcus aureus collagen binding protein in patients with $S$. aureus septicaemia and collagen binding properties of corresponding strains
}

\author{
U. RYDING, B. CHRISTENSSON, B. SODEROUIST* and T. WADSTROM†
}

Department of Infectious Diseases, University Hospital of Lund, "Department of Infectious Diseases, Orebro Medical Centre Hospital and + Department of Bacteriology, University Hospital of Lund, Sweden

\begin{abstract}
Summary. An ELISA was developed for the detection of IgG antibodies to Staphylococcus aureus collagen binding protein (CnBP) in 95 patients with $S$. aureus endocarditis, complicated septicaemia with bone and joint involvement or uncomplicated septicaemia and in 95 control patients. Sixty percent of $S$. aureus-infected patients showed a positive peak anti-CnBP antibody level or a significant rise in titre, or both, during infection, but patients with $S$. aureus endocarditis or complicated septicaemia could not be differentiated from those with uncomplicated $S$. aureus septicaemia. The collagen binding capacity of $S$. aureus strains from 82 of the 95 patients was investigated in a particle agglutination assay and a ${ }^{125} \mathrm{I}$ labelled assay. All strains bound collagen in the particle agglutination assay as did $68 \%$ in the ${ }^{125}$ I-labelled assay, but there was no correlation between collagen binding of the patient strain and endocarditis, joint or skeletal involvement. An anti-CnBP antibody response was seen in 16 patients infected with a $S$. aureus strain negative for collagen binding in vitro, indicating in-vivo expression of $\mathrm{CnBP}$.
\end{abstract}

\section{Introduction}

Specific attachment by various pathogens to extracellular matrix (ECM) proteins are important steps in early tissue colonisation. ${ }^{1}$ Staphylococcus aureus binds to several ECM proteins such as fibronectin, ${ }^{2}$ fibrinogen, ${ }^{3}$ heparan sulphate, ${ }^{4}$ vitronectin, ${ }^{5}$ thrombospondin $^{6}$ and various collagens. ${ }^{7.8} \mathrm{~S}$. aureus is a common pathogen in bone and joint infection as well as in infective endocarditis, ${ }^{9}$ and collagen type $I$ is a major component of bone, cartilage and endocardium. ${ }^{10}$ Recent animal studies have suggested that the collagen binding properties of $S$. aureus strains are correlated with the development of septic arthritis. ${ }^{11} \mathrm{~A}$ 135-kDa collagen binding protein (CnBP) from $S$. aureus Cowan 1 has been purified, characterised and shown to be highly immunogenic in rabbits ${ }^{12}$ and the gene for this protein has been sequenced and cloned. ${ }^{13}$ In the present studies an ELISA was developed with $\mathrm{CnBP}$ as antigen to determine the diagnostic value of IgG antibodies to $\mathrm{CnBP}$ in patients with $S$. aureus septicaemia with and without endocarditis or bone and joint involvement and in control patients. The collagen binding capacity of $S$. aureus strains isolated from patients with endocarditis, complicated septicaemia with bone and joint involvement, and uncomplicated septicaemia was determined.

\section{Materials and methods}

\section{Chemicals}

Tween-20 was obtained from Kebo AB, Spånga, Sweden. Collagen binding protein $(\mathrm{CnBP})$ was purified as described previously ${ }^{12}$ by digestion of bacteria with lysostaphin, ion-exchange chromatography, ammonium sulphate precipitation and gel filtration. It was a kind gift from Dr L. Switalski, School of Dental Medicine, University of Pittsburgh, PA, USA. Rabbit anti-human IgG labelled with alkaline phosphatase was purchased from Dakopatt, Glostrup, Denmark and $p$-nitrophenyl phosphate from Sigma; bovine collagen (Vitrogen $100^{\mathrm{R}}$ containing collagen I $95 \%$ and collagen III $5 \%$ ) was purchased from Collagen Corporation, Paolo Alto, CA, USA; latex beads were purchased from Difco; ${ }^{125}$ iodine was purchased from Amersham Corp.; iodobeads were obtained from Pierce Chemical Co., Rockford, IL, USA and bovine serum albumin (BSA) from Boehringer $\mathrm{GmbH}$, Mannheim, Germany. 
Table I. Age and sex distribution in the various patient groups

\begin{tabular}{lcc}
\hline $\begin{array}{l}\text { Diagnosis } \\
\text { (number of strains) }\end{array}$ & $\begin{array}{c}\text { Mean age (range) } \\
\text { (years) }\end{array}$ & Male/female \\
\hline $\begin{array}{l}\text { S. aureus endocarditis (42) } \\
\text { Complicated } S . \text { aureus } \\
\text { septicaemia (26) }\end{array}$ & $60(22-87)$ & $25 / 17$ \\
Uncomplicated $S$. aureus & $63(20-86)$ & $19 / 7$ \\
septicaemia (27) & $64(24-91)$ & $17 / 10$ \\
Non-S. aureus endocarditis (9) & $62(25-86)$ & $1 / 8$ \\
Non-S. aureus septicaemia (31) & $67(21-89)$ & $10 / 21$ \\
Febrile controls (55) & $54(17-91)$ & $26 / 29$ \\
& & \\
\hline
\end{tabular}

\section{Patients}

All patients were febrile with a temperature $>38.5^{\circ} \mathrm{C}$ for at least 2 days. In all patients with endocarditis or septicaemia, or both, at least two blood cultures were positive.

$S$. aureus endocarditis. Forty-two patients had definite, probable or possible endocarditis according to the criteria of von Reyn et al. ${ }^{14}$ Those who underwent cardiac surgery were regarded as having definite endocarditis if macroscopic vegetations were present on the valves. Three patients had definite, 18 probable and 21 possible endocarditis.

$S$. aureus complicated septicaemia. Twenty-six patients developed infectious involvement of bone or joints as verified by needle aspiration with positive culture, scintigram or X-ray.

S. aureus uncomplicated septicaemia. Twenty-seven patients lacked all signs of bone and joint infection or endocarditis. One patient had septicaemia derived from an intravenous catheter.

Non-S. aureus endocarditis. Nine patients had endocarditis caused by bacteria other than $S$. aureus. Two of these were definite, caused by Enterococcus faecalis and coagulase-negative staphylococci, one had probable endocarditis caused by Streptococcus sanguis and six had possible endocarditis caused by Str. sanguis $(\mathrm{n}=2)$, Str. mitis (1), Str. milleri (1), $\beta$-haemolytic streptococci group G (1) and Str. pneumoniae (1), respectively.

Non-S. aureus septicaemia. Thirty-one patients had septicaemia due to Escherichia coli $(\mathrm{n}=8)$, Str. pneumoniae (5), $\beta$-haemolytic streptococci (5), Pseudomonas aeruginosa (4), coagulase-negative staphylococci (4), Ent. faecalis (2), Salmonella spp. (2) and Proteus mirabilis (1).

Febrile controls. Fifty-five patients with temperatures $>38.5^{\circ} \mathrm{C}$ for at least 2 days and two or more negative blood cultures showed no clinical signs or bacteriological evidence of $S$. aureus infection. Diagnoses were pneumonia $(n=27)$, urinary tract infection (11), erysipelas (7), gastro-enteritis (3), viral infection (3), upper respiratory tract infection (2), sigmoiditis (1) and fever during leukopenia caused by treatment with cytostatic drugs (1). For age distribution and male: female ratio in the various patient groups, see table I.

\section{Serum samples}

Sera were collected at the Departments of Infectious Diseases, University Hospital of Lund and Örebro Medical Centre Hospital, and stored in divided volumes at $-20^{\circ} \mathrm{C}$. Acute sera were drawn within 10 days and convalescent sera 11-30 days after onset of infection (usually onset of fever).

Two hundred and twenty-nine sera were analysed from 95 patients with $S$. aureus septicaemia; in 17 patients only convalescent sera were available. Eighty serum samples were analysed from 40 patients with non-S. aureus endocarditis or septicaemia and from three patients only convalescent sera were available. In the febrile non-septicaemic control group paired sera were available from all 55 patients.

\section{CNBP-ELISA}

Purified CnBP was dissolved in phosphate-buffered saline (PBS, pH 7.2) to a concentration of $0.5 \mu \mathrm{g} / \mathrm{ml}$. Wells of microtitration plates (Maxisorb Nunc, Roskilde, Denmark) were coated with $100 \mu$ l of the antigen solution. Plates were incubated at $37^{\circ} \mathrm{C}$ for $1 \mathrm{~h}$ and washed. Patients' sera were diluted 1 in 2000 in PBS with Tween-20 0.05\%, and $100 \mu \mathrm{l}$ were incubated in each well for $1 \mathrm{~h}$ at $37^{\circ} \mathrm{C}$. After another washing, $100 \mu$ of rabbit anti-human IgG diluted 1 in 2000 in PBS-Tween $0.05 \%$ were added to each well. Plates were incubated for $1 \mathrm{~h}$ on a shaker at room temperature. Finally, plates were washed, incubated with $p$-nitrophenyl phosphate for $30 \mathrm{~min}$ and then read at $405 \mathrm{~nm}$ on a spectrophotometer (Multiskan Plus, Labsystems, Helsinki, Finland). Results were related to a positive control and expressed as the ELISA index.

\section{Bacterial strains}

$S$. aureus septicaemia strains were grown in blood culture bottles, isolated on blood agar plates and stored in calf serum at $-20^{\circ} \mathrm{C}$ until use. Seventeen $S$. aureus strains were available from 18 patients with probable endocarditis, 19 of 21 strains from patients with possible $S$. aureus endocarditis, 23 of 26 strains from patients with complicated and 23 of 27 strains from patients with uncomplicated $S$. aureus septicaemia, respectively. No strains were available from patients with definite endocarditis.

\section{Collagen binding assays}

Particle agglutination assay. A previously described particle agglutination assay (PAA) ${ }^{15}$ was used to screen collagen binding properties of $82 \mathrm{~S}$. aureus strains. The strains were cultured on blood agar which has been shown to increase collagen binding capacity as compared to other media. ${ }^{15}$ S. aureus strain Cowan 1 served as a positive control. Strains were suspended in $0.02 \mathrm{M}$ potassium phosphate buffer $(\mathrm{pH} 6.8)$ to 
c. $10^{10}$ cells $/ \mathrm{ml}$. Latex beads were coated with bovine collagen. One drop of bacterial suspension was mixed with coated latex beads in $0 \cdot 17 \mathrm{M}$ glycine $\mathrm{NaOH}$ buffer (pH 6.8) on a glass slide. Strains were tested for autoaggregation by mixing them with uncoated latex beads. Results were scored from $3+$ when strains agglutinated within $30 \mathrm{~s}, 2+$ within $1 \mathrm{~min}, 1+$ within $2 \mathrm{~min}$ to negative $(-)$ when there was no agglutination within 2 min. $^{16}$

${ }^{125}$ I-collagen binding assay. Bovine collagen was labelled with ${ }^{125} \mathrm{I}$ according to a modified ChloramineT method with Iodobeads ${ }^{\mathrm{R}} \cdot{ }^{16} \mathrm{~S}$. aureus strains were cultured for $24 \mathrm{~h}$ at $37^{\circ} \mathrm{C}$ on blood agar, harvested, washed and resuspended in PBS to $c .5 \times 10^{9} \mathrm{cfu} / \mathrm{ml}$. ${ }^{125} \mathrm{I}$-collagen was diluted to $c .0 .3 \times 10^{4} \mathrm{cpm} / 50 \mu \mathrm{l}$ in PBS with BSA $1 \%$ and added to $100 \mu$ l of bacterial suspension. After mixing, tubes were incubated for $1 \mathrm{~h}$ at room temperature. The binding reaction was stopped by adding $2 \mathrm{ml}$ of PBS + Tween-20 $0 \cdot 1 \% \mathrm{v} / \mathrm{v}$. After centrifugation at $3000 \mathrm{rpm}$ for $15 \mathrm{~min}$ the supernate was aspirated and the radioactivity of the pellet was measured in a 1260 Multigamma counter (LKB-Wallac, Turku, Finland). Results were expressed as percentage radioactivity of total amount of ${ }^{125}$ I-collagen added. S. aureus Cowan 1 served as a positive control.

\section{Statistical analysis}

For evaluation of the reproducibility of an assay, the analytical error was calculated. The inter-assay error was expressed as the standard deviation of the single determination $\mathrm{s}= \pm \sqrt{\left(\mathrm{Sd}^{2} / 2 n\right)}$ where $\mathrm{Sd}^{2}$ equals the squared sum of differences within pairs and $n$ equals the number of pairs. Since the absolute differences within paired observations in the CnBP. ELISA rose with higher optical density values, the standard deviations of the single determinations in this assay were calculated as percentage values. The $\chi^{2}$ test was used to compare differences in anti-CnBP levels in various patient groups and collagen binding capacity in strains from patients with $S$. aureus endocarditis, complicated and uncomplicated septicaemia.

\section{Results}

The upper normal anti-CnBP IgG level was defined as the mean value of the febrile control group $+2 \mathrm{SD}$. This gave an upper normal ELISA index of 0.712. As shown in fig. 1 and table II, peak anti-CnBP IgG levels above cut-off were found in $12(57 \%)$ of 21 patients with definite or probable $S$. aureus endocarditis, 9 $(43 \%)$ of 21 patients with possible $S$. aureus endocarditis, $9(35 \%)$ of 26 patients with $S$. aureus complicated septicaemia, $8(30 \%)$ of 27 patients with $S$. aureus uncomplicated septicaemia and $3(5 \%)$ of 55 febrile control patients. No patients with non- $S$. aureus endocarditis or septicaemia showed a positive peak antibody level. The analytical error of the method was $21 \%$ and a significant rise in titre between acute and convalescent sera was defined as $>50 \%$ increase of ELISA index. Positive peak anti-CnBP titres or a significant titre rise, or both, were found in $43(63 \%)$ of $68 \mathrm{~S}$. aureus infected patients with endocarditis or bone and joint infection as compared to $14(52 \%)$ of 27 patients with uncomplicated $S$. aureus septicaemia (table II). This difference was not significant ( $p>0.05$ ). No patients with non-S. aureus endocarditis was positive, but two patients with $P$. aeruginosa and one with Str. pneumoniae septicaemia showed significant rises in titre. Thus, the specificity for diagnosing $S$. aureus endocarditis or septicaemia, or both, was $92 \%(37$ of 40$)$ in the present studies.

Six $S$. aureus strains auto-aggregated in the PAA and all the remaining 76 strains bound collagen (table III). Sixty-two strains were run on several different occasions, and $13(21 \%)$ strains changed from $1+$ to $2+$ or $3+$ or vice versa. The analytical error of the ${ }^{125} \mathrm{I}$ collagen binding assay was $2.5 \%$, background was $1.7 \%$ and values below $2 \times 2.5 \%+1.7 \%=6.7 \%$ were regarded as negative for collagen binding. Fourteen $(82 \%)$ of $17 \mathrm{~S}$. aureus strains from patients with probable endocarditis were positive as were $12(63 \%)$ of 19 strains from patients with possible endocarditis, $16(70 \%)$ of 23 strains from patients with complicated and $15(65 \%)$ of 23 strains from patients with uncomplicated $S$. aureus septicaemia (table III). There was poor correlation between the two collagen binding assays where 10 of 37 strains classified as $3+$ showed no ${ }^{125}$ I-collagen binding capacity (fig. 2 ).

There was no significant correlation $(p>0.05)$ between the development of endocarditis or joint and skeletal infection and the collagen binding capacity of corresponding strains of $S$. aureus with either collagen binding assay (table III). Fifty-one strains were available from patients seropositive for anti-CnBP, among which $16(31 \%)$ were found negative in the ${ }^{125} \mathrm{I}-$ collagen binding assay. The patients infected with these 16 strains developed positive peak anti-CnBP antibody level $(n=8)$, rise in titre (3) or both (5).

\section{Discussion}

Many serological assays with various $S$. aureus antigens have been published over the last decade with the purpose of finding an assay or a combination of assays that could distinguish patients with complicated septicaemia, including endocarditis and deep-seated tissue infections, from those with uncomplicated septicaemia. ${ }^{17-21}$ No single assay has so far proved to be adequate for this differential diagnosis, but combinations of assays have in some cases reached acceptable predictive values. ${ }^{22-25}$

In the present studies an ELISA was developed to determine the IgG antibody response towards $S$. aureus CnBP. Detectable antibodies to $\mathrm{CnBP}$ were 


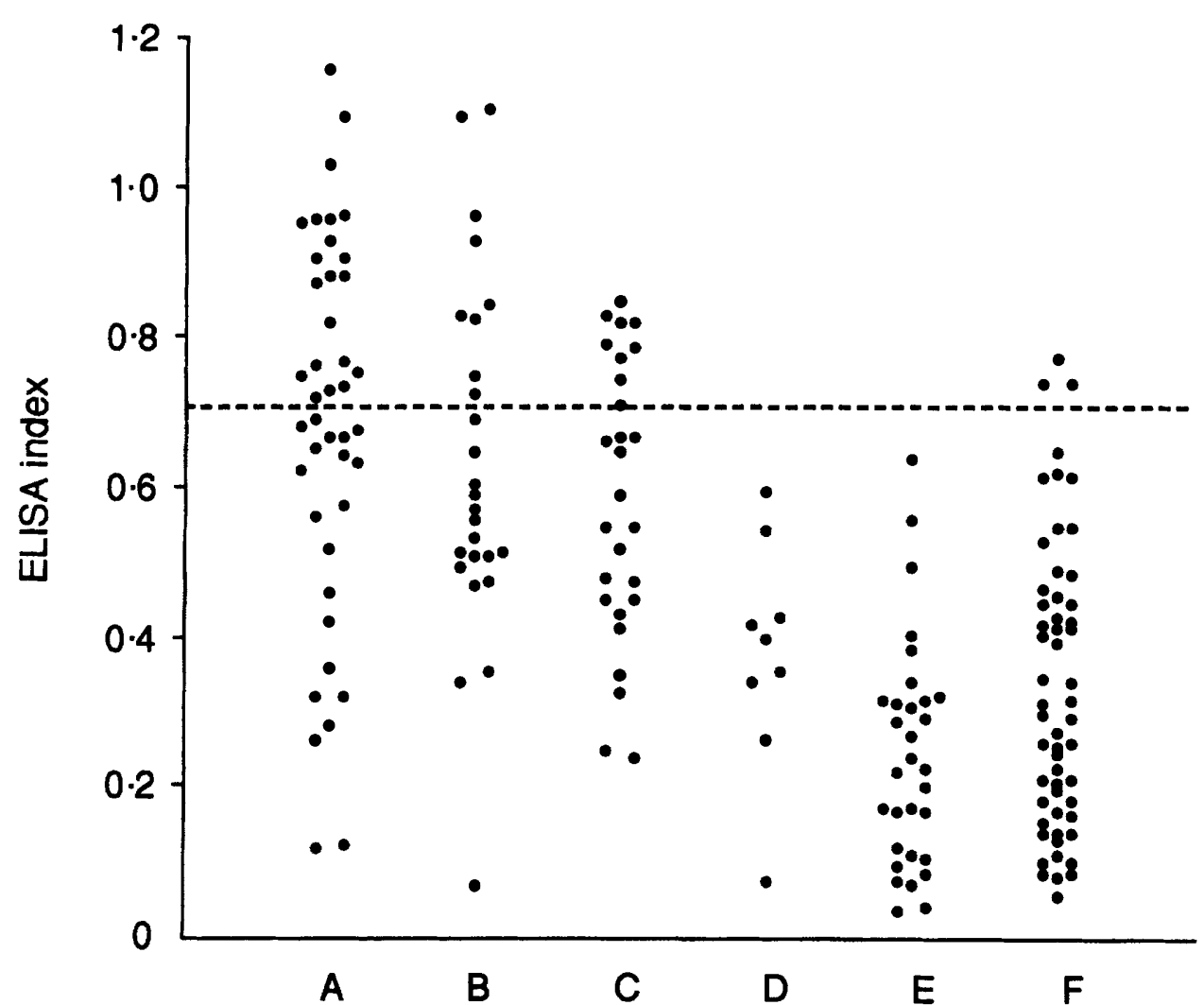

Patient group

Fig. 1. Levels of IgG antibody to $S$. aureus collagen binding protein (CnBP) measured by ELISA. Peak antibody levels are shown from patients with $S$. aureus endocarditis $(\mathrm{A}, \mathrm{n}=42)$, S. aureus complicated septicaemia $(\mathrm{B}, \mathrm{n}=26)$, S. aureus uncomplicated septicaemia $(\mathrm{C}, \mathrm{n}=27)$, non$S$. aureus endocarditis $(\mathrm{D}, \mathrm{n}=9)$, non-S. aureus septicaemia $(\mathrm{E}, \mathrm{n}=31)$ and febrile controls $(\mathrm{F}, \mathrm{n}=55) ;----$, upper normal anti-CnBP-IgG level defined as mean value of the febrile control group $+2 \mathrm{SD}$.

Table II. Number of patients with positive peak anti-CnBP ELISA index or significant rise in titre during the course of infection, or both

\begin{tabular}{lccc}
\hline Diagnosis & Number of & Number (\%) of patients with \\
\cline { 3 - 4 } & patients & $\begin{array}{c}\text { Positive peak } \\
\text { ELISA index } \\
\text { or significant titre rise, or both }\end{array}$ & $15(71)$ \\
S. aureus definite or probable & 21 & $12(57)$ & $15(71)$ \\
endocarditis & 21 & $9(43)$ & $13(50)$ \\
S. aureus possible endocarditis & 26 & $8(35)$ & $14(52)$ \\
$S$. aureus complicated septicaemia & 27 & $0(0)$ & $0(0)$ \\
$S$. aureus uncomplicated & 9 & $3(0)$ & $3(10)$ \\
septicaemia & 31 & 55 & $3(5)$
\end{tabular}

found in all $S$. aureus-infected patients as well as in controls (fig. 1), which has also been reported with serological assays with various $S$. aureus antigens. ${ }^{17-21}$ Cross-reacting antibodies in non- $S$. aureus endocarditis or septicaemia were seen in only $3(8 \%)$ of 40 patients, two patients with $P$. aeruginosa septicaemia and one patient with Str. pneumoniae septicaemia showing a significant rise in titre although not reaching a positive peak antibody level. Thus, this assay seems to be highly specific for $S$. aureus infection, and contrary to, for example, assays with $S$. aureus teichoic acid, peptidoglycan, crude $S$. aureus antigen, whole $S$. aureus cells and $\alpha$-toxin, ${ }^{20-22,24}$ no cross-reacting antibodies were seen in patients with endocarditis or septicaemia due to $\alpha$-streptococci, enterococci or coagulase-negative staphylococci. This could be due to the use of a highly purified protein specific for S. aureus.

The overall sensitivity in diagnosing $S$. aureus endocarditis or septicaemia was $60 \%$ (57 of 95) (table 
Table III. Binding of collagen to $S$. aureus strains from patients with endocarditis, complicated and uncomplicated septicaemia

\begin{tabular}{|c|c|c|c|c|c|}
\hline \multirow{2}{*}{ Diagnosis } & \multirow{2}{*}{$\begin{array}{l}\text { Number } \\
\text { of strains }\end{array}$} & \multicolumn{3}{|c|}{$\begin{array}{l}\text { Number }(\%) \text { of particle } \\
\text { agglutinating strains }\end{array}$} & \multirow{2}{*}{$\begin{array}{l}\text { Number (\%) of } \\
{ }^{125} \text { I-collagen binding strains }\end{array}$} \\
\hline & & +++ & ++ & + & \\
\hline $\begin{array}{l}\text { Probable } \\
\text { endocarditis }\end{array}$ & 17 & $7(41)$ & $2(12)$ & $6(35)$ & $14(82)$ \\
\hline $\begin{array}{l}\text { Possible } \\
\text { endocarditis }\end{array}$ & 19 & $8(42)$ & $5(26)$ & $5(26)$ & $12(63)$ \\
\hline $\begin{array}{c}\text { Complicated } \\
\text { septicaemia }\end{array}$ & 23 & $15(65)$ & $2(9)$ & $5(22)$ & $16(70)$ \\
\hline $\begin{array}{l}\text { Uncomplicated } \\
\text { septicaemia }\end{array}$ & 23 & $7(30)$ & $7(30)$ & $7(30)$ & $15(65)$ \\
\hline
\end{tabular}

Six strains autoagglutinated in the PAA, two were from patients with probable endocarditis, one from a patient with possible endocarditis, one from a patient with complicated septicaemia and two from patients with uncomplicated septicaemia.

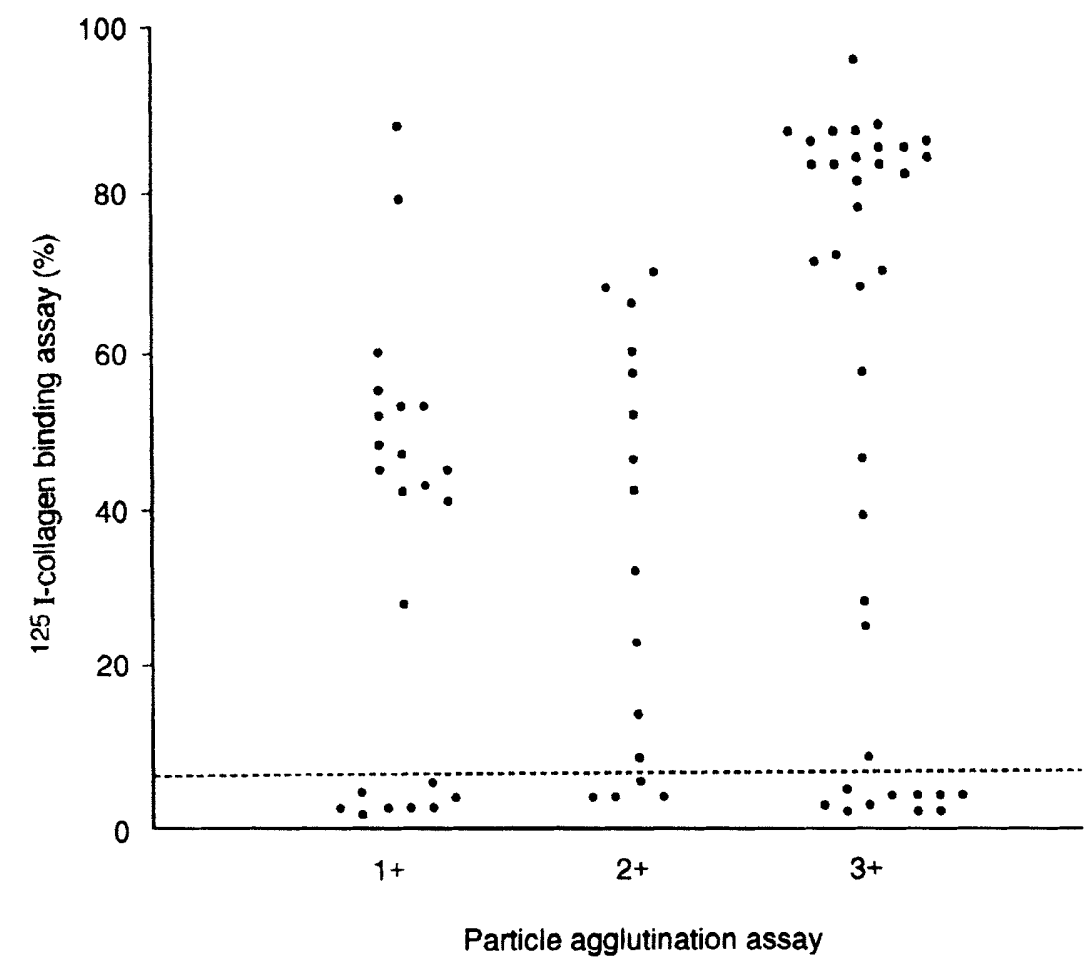

Fig. 2. Correlation between collagen binding measured with ${ }^{125}$ I-collagen and particle agglutination assay in $S$. aureus strains from patients with endocarditis, complicated and uncomplicated septicaemia. Values below the dashed line (---) indicate negative result in the ${ }^{125} \mathrm{I}$-collagen binding assay.

II), which is similar to the results of several other serological assays ${ }^{17-19.21}$ and indicates that CnBP is highly immunogenic. It was assumed that patients with $S$. aureus endocarditis or complicated septicaemia would show increased anti-CnBP levels based on the expected increase in CnBP expression when $S$. aureus adheres to the collagen of endocardium, bone and cartilage. However, there was no significant difference in antibody levels among these patients as compared to those with $S$. aureus uncomplicated septicaemia $(p>0.05)$, and thus the anti-CnBP ELISA could not be used as a single assay to differentiate between such patient groups.
In previous studies a correlation between $S$. aureus endocarditis, arthritis and osteomyelitis and high collagen binding capacity of corresponding $S$. aureus strains has been suggested. In an animal model, intravenous challenge of $S$. aureus strain Phillips expressing CnBP caused septic arthritis in all of 10 mice, as compared to 5 of 10 mice challenged with a mutant strain not expressing CnBP. ${ }^{11}$ With ${ }^{125} \mathrm{I}$ collagen, Holderbaum et al. ${ }^{26}$ have previously reported a significantly higher proportion (26 of 49 ) of high collagen binding strains in bacteraemic patients with $S$. aureus endocarditis, arthritis and osteomyelitis as compared to those with no evidence of metastatic 
infection (13 of 41). The authors did not give diagnostic criteria for their patients with endocarditis, joint or skeletal infection and their septicaemic patients without signs of metastatic infections all had infected intravenous catheters. In the present studies, a similar ${ }^{125}$ I-collagen binding assay was used but no difference in the collagen binding capacity of $S$. aureus strains from patients with or without endocarditis or bone or joint infection was found (table III). One possible reason for this discrepancy could be that $S$. aureus strains colonising intravenous catheters differ in their collagen binding capacity from other septicaemia strains. However, all strains studied, except for six autoagglutinating strains, were positive in the PAA, and it could be argued that the PAA better reflects in-vivo conditions (collagens do not appear in solution in vivo ${ }^{10}$ ).

Furthermore, 16 patients infected with $S$. aureus strains negative in the ${ }^{125} \mathrm{I}$-collagen binding assay who had positive anti-CnBP antibody levels $(n=8)$, significant rises in titre $(n=3)$ or both $(n=5)$ were found. These results indicate in-vivo expression of $\mathrm{CnBP}$ in in-vitro negative strains. It is of interest to note that inconsistencies between antibody response and expression of $S$. aureus antigen have been reported previously. Rollof et al. found no significant difference in lipase activity between septicaemic strains from 22

\section{References}

1. Beachey EH. Bacterial adherence: adhesion-receptor interactions mediating the attachment of bacteria to mucosal surfaces. J Infect Dis 1981; 143: 325-345.

2. Kuusela P. Fibronectin binds to Staphylococcus aureus. Nature 1978; 276: 718-720.

3. Bodén MK, Flock J-I. Fibrinogen-binding protein/clumping factor from Staphylococcus aureus. Infect Immun 1992; 57 : 2358-2363.

4. Liang OD, Ascencio F, Fransson L- $\AA$, Wadström T. Binding of heparan sulphate to Staphylococcus aureus. Infect Immun 1992; 60: 899-906.

5. Paulsson $M$, Liang OD, Ascencio F, Wadström $T$. Vitronectinbinding surface proteins of Staphylococcus aureus. Zentralbl Bakteriol 1992; 277 : 54-64.

6. Herrmann M, Suchard SJ, Boxer LA, Waldvogel FA, Lew PD. Thrombospondin binds to Staphylococcus aureus and promotes staphylococcal adherence to surfaces. Infect Immun 1991; 59: 279-288.

7. Speziale $P$, Höök $M$, Wadström T. Binding of type II collagen to staphylococci. In: Jeljascewicz J (ed) The staphylococci, Zentralbl Bakteriol Suppl 14. Stuttgart, New York, Gustav Fischer Verlag. 1985: 191-196.

8. Vercelotti GM, McCarthy JB, Lindholm P, Peterson PK, Jacob HS, Furcht LT. Extracellular matrix proteins (fibronectin, laminin, and type IV collagen) bind and aggregate bacteria. Am J Pathol 1985; 120 : 13-21.

9. Sheagren JN. Staphylococcus aureus. The persistent pathogen. N Engl J Med 1984; 310: 1368-1373.

10. Miller EJ, Gay S. The collagens: An overview and update. In: Cunningham LW (ed) Structural and contractile proteins. Part D, Extracellular matrix. Methods in enzymology, vol. 144. Orlando, FL, Academic Press. 1987: 3-41.

11. Patti JM, Bremell T, Krajewska-Pietrasik D et al. The Staphylococcus aureus collagen adhesin is a virulence determinant in experimental septic arthritis. Infect Immun 1994; 62 : 152-161.

12. Switalski LM, Speziale $P$, Höök M. Isolation and characterization of a putative collagen receptor from Staphylococcus patients positive in an anti-lipase ELISA and strains from 16 serologically negative patients. ${ }^{27}$ In a recently published study no correlation was demonstrated between antibody response to $\alpha$-toxin in patients with $S$. aureus septicaemia and $\alpha$-toxin production in vitro by the corresponding strain. ${ }^{28}$ However, in both these studies all strains produced at least low amounts of the antigens.

In conclusion, in patients with $S$. aureus septicaemia we were unable to show a correlation between the bone, joint or cardiac involvement and the in-vitro collagen binding capacity of the patient strain. The anti-CnBP ELISA was highly specific for $S$. aureus infection and might aid in the diagnosis of $S$. aureus endocarditis or septicaemia but cannot be used as a single assay in differentiating between endocarditis or complicated septicaemia and uncomplicated septicaemia. An ongoing study will determine the value of the anti-CnBP ELISA in combination with various other serological assays in the diagnosis of serious $S$. aureus infections.

We thank Dr L. Switalski for providing CnBP and Barbro Zeeberg and Martina Rignèr for excellent technical assistance. This work was supported by grants from the Medical Faculty at the University of Lund, by a grant from Swedish Medical Research Council (16 X-04723) to T.W. and by a grant from Svenska Upjohn AB to U.R.

aureus strain Cowan 1. J Biol Chem 1989; 264: 2108021086.

13. Patti JM, Jonsson H, Guss B et al. Molecular characterization and expression of a gene encoding a Staphylococcus aureus collagen adhesin. $J$ Biol Chem 1992; 267: 4766-4772.

14. von Reyn CF, Levy BS, Arbeit RD, Friedland G, Crumpacker CS. Infective endocarditis: an analysis based on strict case definitions. Ann Intern Med 1981; 94: 505-518.

15. Naidu AS, Paulsson M, Wadström T. Particle agglutination assays for rapid detection of fibronectin, fibrinogen, and collagen receptors on Staphylococcus aureus. J Clin Microbiol 1988; 26: 1549-1554.

16. Markwell MAK. A new solid-state reagent to iodinated proteins. 1. Conditions for the efficient labeling of antiserum. Anal Biochem 1982; 125 : 427-432.

17. Brakstad OG, Maeland JA, Wergeland HI. Serum antibodies to a Staphylococcus aureus thermonuclease preparation in healthy persons and patients with bacteremia. Serodiagn Immunother Infect Dis 1989; 3: 201-210.

18. Christensson B, Fehrenbach FJ, Hedström SÅ. A new serological assay for Staphylococcus aureus infections: detection of IgG antibodies to $S$. aureus lipase using enzymelinked immunosorbent assay. $J$ Infect Dis 1985; 152: 286-292.

19. Greenberg DP, Bayer AS, Turner D, Ward JI. Antibody responses to Protein A in patients with Staphylococcus aureus bacteremia and endocarditis. J Clin Microbiol 1990; 28: $458-462$

20. Jarløv JO, Christensson B, Espersen F, Hertz JB, Hedström SÅ. Antibody response against whole Staphylococcus aureus in patients with staphylococcal septicemia and endocarditis investigated by ELISA. Acta Pathol Microbiol Immunol Scand Sect B 1985; 93: 307-313.

21. Julander IG, Granström M, Hedström SÅ, Möllby R. The role of antibodies against alpha-toxin and teichoic acid in the diagnosis of staphylococcal infections. Infection 1983; 11: $77-83$.

22. Christensson B, Espersen F, Hedström SÅ, Kronvall G. Serological assays against Staphylococcus aureus peptidoglycan, crude staphylococcal antigen and staphylolysin in 
the diagnosis of serious $S$. aureus infections. Scand J Infect Dis $1985 ; 17: 47-53$

23. Christensson B. Serological diagnosis of staphylococcal bacteremia. Lancet 1986; 2: 1165-1166.

24. Ryding U, Renneberg J, Rollof J, Christensson B. Antibody response to Staphylococcus aureus whole cell, lipase and staphylolysin in patients with $S$. aureus infections. FEMS Microbiol Immunol 1992; 4: 105-110.

25. Verbrugh HA. Nelson RD, Peterson PK, Wilkinson BJ, Thompson RL. Serology of Staphylococcus aureus infections using multiple antigens and serial serum samples. $J$ Infect Dis 1983; 148: 608 .
26. Holderbaum D, Spech T, Ehrhart LA, Keys T, Hall GS. Collagen binding in clinical isolates of Staphylococcus aureus. J Clin Microbiol 1987; 25 : 2258-2261.

27. Rollof J, Hedström SÅ, Nilsson-Ehle P. Lipolytic activity of Staphylococcus aureus strains from disseminated and localized infections. Acta Pathol Microbiol Immunol Scand Sect $B$ 1987; 95: 109-113.

28. Söderquist $B$, Colque-Navarro $P$, Blomqvist $L$, Olcén $P$, Holmberg H, Möllby R. Staphylococcal alpha-toxin in septicaemic patients; detection in serum, antibody response and production in isolated strains. Serodiagn Immunother Infect Dis 1993; 5: 139-144. 